\title{
STAKEHOLDERS: PRINCIPAIS ABORDAGENS
}

\author{
Stakeholders: main approaches
}

Patrícia Mattos de Barros Schiavoni

Doutora em Engenharia de Produção, Universidade Federal de Santa Catarina - Florianópolis - SC - Brasil. E-mail: pbarrosschiavoni@ gmail.com

\section{Mário Cesar Barreto Moraes}

Professor do Programa de Pós-Graduação em Administração, Universidade do Estado de Santa Catarina - Florianópolis - SC - Brasil. E-mail: mcbmstrategos@gmail.com

\section{Alice Carneiro de Castro}

Mestre em Administração de Empresas, Universidade do Estado de Santa Catarina - Florianópolis - SC - Brasil.E-mail: alice_adm@ yahoo.com.br

\section{Jair Nascimento Santos}

Doutor em Administração, Professor do Programa de Pós graduação em Administração, Universidade de Salvador - Salvador - BA -

Brasil. E-mail: jair.santos@unifacs.br

\section{Resumo}

A cada momento as organizações necessitam de adaptações para se manterem vivas. Considera-se a análise de seu ambiente externo uma ferramenta essencial nesse processo adaptativo e, em especial, é primordial conhecer seus stakeholders. O presente artigo tem por objetivo apresentar diferentes abordagens sobre stakeholders organizacionais, contribuindo concomitantemente com a academia e com as empresas que optarem por analisar e agir sobre seus grupos de interesse e, possivelmente, para ter um destaque no mercado. Destaca-se a abordagem de gestão dos stakeholders, de Edward Freeman; o modelo das relações corporativas com os stakeholders, de Ann Svendsen; e a abordagem do comprometimento dos stakeholders, de Steven Walker e Jeffrey Marr.

Palauras-chave: Stakeholders. Gestão dos Stakeholders. Relações Corporativas. Comprometimento.

\section{AbStRACT}

Every time organizations need adaptations to stay alive. We consider the analysis of their external environment an essential tool in this adaptive process, in particular, know your stakeholders. This article aims to present different approaches to organizational stakeholders, contributing concurrently with academia and companies who choose to analyze and act on its stakeholders, and possibly have a prominent market. We highlight the approach of stakeholder management, Edward Freeman, the model of corporate relations with stakeholders Ann Svendsen approach and commitment of stakeholders, Steven Walker and Jeffrey Marr.

Keywords: Stakeholders. Stakeholder Management. Corporate Relations. Commitment. 


\section{INTRODUÇÃo}

O propósito deste artigo é desenvolver uma revisão das abordagens sobre stakeholders. Para tanto, considera-se essencial a apresentação de um tema que embasará tal assunto, qual seja, a organização e seu ambiente externo.

No presente artigo utiliza-se a visão da organização como sistema, da qual,

Qualquer organização pode ser vista como um sistema aberto ao adquirir do meio que a envolve energia, informação e materiais. O sistema processa tais insumos (entradas) e vende ao meio os produtos ou os serviços (saídas) resultantes do processamento. Os insumos representam os custos. Os produtos ou serviços dão origem às receitas. $O$ processo desenvolvido pela empresa representa o valor agregado pelo sistema. Por conseguinte, as receitas devem cobrir não só os custos, mas também o valor agregado. Surge, então, a oportunidade de definir o importante conceito de produtividade: trata-se da relação entre as saídas e as entradas. Ou entre as receitas e os custos. (PETROCCHI, 2001, p. 27)

Assim, quando se estuda a organiszação como um sistema, podem-se obter diretrizes para a sua gestão e evidenciar as condições necessárias à sua sobrevivência por meio da produtividade. (PETROCCHI, 2001)

O enfoque sistêmico trata as organizações como sistemas dependentes que precisam relacionar-se de maneira adequada com seu ambiente externo, garantindo os recursos para sua sobrevivência e desenvolvimento, assim como os organismos vivos que precisam estabelecer relações com o ambiente externo para suprir suas necessidades básicas. (STONER; FREEMAN, 1995)

De acordo com Katz e Khan (1987), Perrow (1972) e Pfeffer e Salancik (1978), a organização pode ser definida como uma coalizão de grupos de interesses mutantes, que visam atingir suas próprias metas no contexto do ambiente mais amplo. Dessa forma, as organizações são vistas como dependentes de recursos do ambiente externo. Por um lado, a organização pode obter do ambiente externo os recursos materiais e humanos necessários ao seu funcionamento (matéria-prima, capital, mão de obra) e, de outro, comercializar seus produtos e serviços. (CROZIER; FRIEDBERG, 1977)

O ambiente externo era menosprezado pelas teorias clássicas da administração. Como naquela época, primeira metade do século $\mathrm{XX}$, o ambiente era caracterizado pela estabilidade e previsibilidade, a preocupação era concentrada no ambiente interno organizacional. Atualmente, a turbulência e a inconstância são características marcantes do ambiente, tornando fundamental a análise deste para a evolução e a sobrevivência de qualquer organização.

Oliveira (2013, p. 26) define como ambiente externo o "[...] conjunto de todos os fatores que, dentro de um limite específico, se possa conceber como tendo alguma influência sobre a operação do sistema". Oliveira (2001) complementa dizendo que o ambiente de um sistema é o conjunto de elementos que não pertencem ao sistema, mas qualquer alteração no sistema pode mudar ou alterar os elementos; e qualquer alteração nos elementos pode mudar ou alterar o sistema.

Miles (1980) pondera que, ao analisar o ambiente, existe a necessidade de se distinguir os elementos que possuem relevância direta para a organização, ou seja, os que fazem parte do ambiente específico da organização, daqueles que exercem influência indireta sobre ela e que fazem parte do ambiente geral. Stoner e Freeman (1995) denominam, respectivamente, de ambiente direto e indireto.

Os elementos do ambiente geral podem ser classificados em políticos, econômicos, sociais e tecnológicos e influenciam todas as organizações (FAHEY; NARAYANAN apud STONER; FREEMAN, 1995). Alperstedt (2002) reconhece tal ambiente como macroambiente e, acrescenta, além dos elementos supracitados, os de natureza demográfica, cultural, legal e ecológica.

Em contrapartida, o ambiente específico varia em função das atividades exercidas pela organização, tais como os produtos e os serviços oferecidos e os mercados atendidos Fazem parte desse ambiente os fornecedores, acionistas, consumidores, distribuidores, Governo, sindicatos, associações de classe, veículos de comunicação, concorrentes, comunidade (BOWDITCH; BUONO, 1992). Bowditch e Buono (1992) afirmam que tal conceito ressalta a necessidade de se entender a relação das organizações com os diversos grupos sociais afetados pela sua operação (stakeholders), tendo em vista que a natureza de tais 
relacionamentos varia de acordo com a intensidade, a duração e o significado.

\section{A Evolução do Termo Stakeholder}

Pode-se localizar, sem uma comprovação exata, a primeira menção do termo stakeholder num memorando interno do Stanford Research Institute (SRI) em 1963 (atualmente SRI International, Inc.), o qual se referia ao grupo cujo apoio faltasse a organização não sobreviveria. O termo também foi citado por Igor Ansoff e Robert Stewart no departamento de planejamento da Lockheed e, posteriormente, por Marion Doscher e Robert Stewart na empresa norte-americana SRI. A partir de então, o termo stakeholder foi utilizado para definir várias direções. (FREEMAN, 1984)

Freeman (1984) acrescenta que na mesma década de 1960, o termo também foi citado em trabalhos de consultores e pesquisadores e, destacadamente, nos trabalhos de Eric Rhenman, na Suécia, que aplicou os conceitos para a democracia industrial.

Nos anos de 1970, pesquisadores da teoria dos sistemas, tendo Russel Ackoff como líder, "redescobriram" o termo. Ackoff afirmou que muitos problemas sociais podem ser solucionados pelo redesenho dos fundamentos das instituições com o suporte e a interação do stakeholder no sistema. (FREEMAN, 1984)

Os anos de 1970 iniciaram com a criação de um projeto de alguns pesquisadores de Harvard, na área da responsabilidade social das organizações. O resultado foi o desenvolvimento de um modelo pragmático de responsabilidade social chamado $O$ Modelo de Responsabilidade Social das Corporações, enfocando como uma corporação que pode responder, de maneira proativa, às pressões para uma mudança social positiva. (FREEMAN, 1984)

Em 1977, a Wharton School inicia um projeto denominado Stakeholder Project, cujo objetivo era desenvolver um modelo teórico de gerenciamento que possibilitasse a formulação $e$ implementação de estratégias corporativas, pelos executivos, em um ambiente tumultuado. (KLUGE; PEPPLOW, 2005)

A disseminação do termo stakeholder teve seu início no final dos anos de 1980 e como marco, destaca-se o trabalho de R. Edward Freeman, Strategic Management: a Stakeholder Approach, publicado em
1984. A teoria objetivava oferecer aos empresários e aos executivos uma ferramenta para compreensão dos interesses e dos desejos do "outro" - stakeholders; que eram definidos como os indivíduos afetados e/ou interessados, direta ou indiretamente, pelos empreendimentos econômicos - e para aprender a lidar com eles de maneira estratégica e a gerenciar as diversas percepções e interesses. Freeman (1984, p. 48) afirma que "The stakeholder approach is about groups and individuals who can affect the organization, and is about managerial behavior taken in response to those groups and individuals".

De acordo com Freeman (1984), para desenvolver estratégias, a organização deveria buscar resposta a três perguntas básicas sobre seus stakeholders: Quem são eles? (seu perfil, atributos e características de comportamento); O que eles querem? (refere-se aos seus interesses e metas); Como eles tentarão atingir suas metas e satisfazer seus interesses? (esta questão é relativa aos meios para se alcançar os fins).

Pfeffer e Salancik (1978) afirmam que as organizações sobrevivem de acordo com sua efetividade, a qual se origina do gerenciamento das necessidades dos grupos de interesse (stakeholders), que estabelecem relações de dependência de recursos e apoio com a organização, e de sua habilidade de obter resultados e criar ações por eles aceitas. Logo, as organizações necessitam tratar com sensibilidade as demandas de seus ambientes e as demandas dos stakeholders que apoiam sua manutenção e desenvolvimento, buscando um equilíbrio em seus relacionamentos com esses diversos stakeholders.

\section{Abordagens sobre Stakeholders}

De acordo com Freeman (1984), a gestão dos stakeholders como um conceito, refere-se à necessidade de uma organização gerenciar as relações com seus específicos grupos de stakeholder por meio de uma ação orientada.

Freeman (1984) afirma que a definição de stakeholder como qualquer grupo ou indivíduo que pode afetar ou é afetado pelo alcance dos objetivos da organização aumenta a necessidade de processos e técnicas para intensificar a capacidade de gestão estratégica da organização. Assim, pondera-se existir 
pelo menos três níveis, dos quais se podem entender os processos que uma organização utiliza para gerenciar as relações com seus stakeholders, a saber:

a) Nível racional - deve-se entender de maneira racional, quem são os stakeholders da organização e quais são seus interesses percebidos.

b) Nível processual - é preciso entender os processos organizacionais utilizados para qualquer gestão das relações da organização com seus stakeholders (implícita ou explicita), e se esses processos se encaixam com o mapa racional dos stakeholders da organização.

c) Nível transacional - deve-se entender o conjunto de transações ou barganhas entre a organização e seus stakeholders e deduzir se essas negociações se encaixam com o mapa deles e com os processos organizacionais para eles.

Freeman (1984) observa que se pode definir a capacidade de gestão dos stakeholders de uma organização através da sua habilidade de colocar estes três níveis de análises juntos. Por exemplo, uma organização que entende seu mapa dos stakeholders e os interesses de cada grupo, da qual possui processos organizacionais que levam em conta rotineiramente esses grupos e seus interesses como parte de procedimentos operacionais padronizados da organização, e da qual implementa um conjunto de transações ou barganhas para equilibrar os interesses dos stakeholders para o alcance dos objetivos da organização, supostamente terá uma maior, ou superior, capacidade de gestão de stakeholder.

Por outro lado, Freeman (1984) acrescenta que a organização que não entende quem são seus stakeholders, não possui processos padronizados para se relacionar com seus interesses e que não tem um conjunto de transações para negociar com seus stakeholders, supostamente, terá uma menor, ou inferior, capacidade de geri-los. A seguir serão apresentados detalhadamente os três níveis de análise dos stakeholders.

\subsection{Nível Racional}

Qualquer ferramenta que busca um incremento na capacidade de gestão dos stakeholders de uma organização deve iniciar a aplicação a partir da definição básica. Quem são os grupos ou indivíduos afetados ou que afetam o alcance dos objetivos da organização?
Como se pode construir um mapa dos stakeholders da organização? Quais são os obstáculos na construção de tal mapa?

A Ilustração 1 serve como base inicial para a construção do mapa dos stakeholders de uma empresa tradicional.

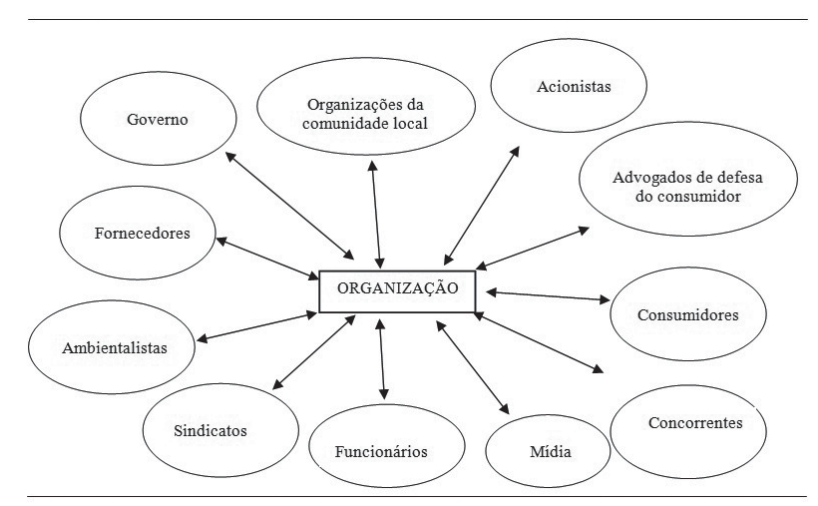

Ilustração 1: A visão dos stakeholders da organização Fonte: Adaptada de Freeman (1984, p. 25)

Para a construção do mapa para negócios particulares, Freeman (1994) aconselha que o ideal seria iniciar por uma análise histórica do ambiente dessa firma em particular. Na ausência desse histórico, o mapa da Ilustração 1 pode servir como um ponto de referência para um mapa inicial genérico dos stakeholders. Posteriormente, devem-se analisar os interesses de cada um dos grupos específicos de stakeholders listados no mapa.

Freeman (1984) pondera que os stakeholders são ligados à organização por meio de uma complexa rede e entre si. Assim, possuem algumas implicações quais sejam: um assunto particular pode unir vários stakeholders - tendo o apoio ou a oposição deles à política da organização. E, ainda, as organizações poderão utilizar tais redes para influenciar, indiretamente, outros stakeholders. Outro fato é que alguns membros de um grupo de stakeholders podem ser membros de outros grupos, e na qualidade de stakeholder em uma organização, deve equilibrar (ou não) conflitos e competições de papéis.

Carrol (1993) e Svendesen (1998) apontam que dentre os grupos de interesse estão os que a empresa estabelece relações contratuais, classificados como primários e que são diretamente influenciados pelas ações empresariais. Nesse grupo destacam-se os acionistas, os funcionários, os clientes, os fornecedores, a comu- 
nidade e o meio ambiente, entre outros. Os demais stakeholders estão inseridos nos grupos secundários, que não são diretamente influenciados pela organização. Nesse grupo, são citados como exemplos os grupos de pressão e a mídia. Gibson (2000) complementa destacando que os gestores devem levar em conta o interesse de ambos os grupos, desde que sejam capazes de influenciar, de maneira significativa, as atividades da organização.

Um modelo analítico, proposto por Freeman (1984) e apresentado no Quadro 1 a seguir, representa os stakeholders de uma organização em uma grade de duas dimensões. A primeira dimensão classifica os stakeholders pelos seus interesses ou ações, ou seja, existem três tipos de stakeholders: os proprietários (possuem interesses iguais); clientes e fornecedores (possuem interesses de mercado); e o Governo (possui um interesse em como a firma atua, pois ela o afeta de alguma maneira). A segunda dimensão da grade classificatória pode ser entendida em termos de poder, a habilidade de usar os recursos para fazer um evento acontecer. Os três pontos de interesse desta dimensão são poder de voto (proprietários podem gastar seus recursos votando em diretores, ou para apoiar a gerência), poder econômico (clientes e fornecedores podem gastar seus recursos medindo o investimento em $P \& D$, ligando-se a outra firma, baixando preços), e poder político (o Governo pode gastar seus recursos escrevendo novas regulamentações e aprovando legislação).

\begin{tabular}{|c|c|c|c|}
\hline INTERESSE & $\begin{array}{c}\text { FoRMAL OU } \\
\text { DE VOTO }\end{array}$ & Econômico & Político \\
\hline Equidade & $\begin{array}{l}\text { Acionistas } \\
\text { Diretores } \\
\text { Minoria } \\
\text { interessada }\end{array}$ & $\begin{array}{l}\text { Clientes } \\
\text { Competidores } \\
\text { Fornecedores }\end{array}$ & \\
\hline Econômico & $\begin{array}{l}\text { Credores } \\
\text { Unions }\end{array}$ & \multicolumn{2}{|c|}{ Governos estrangeiros } \\
\hline Influenciadores & & & $\begin{array}{l}\text { Consumidor } \\
\text { Advogados } \\
\text { Governo } \\
\text { Nader's } \\
\text { Raiders } \\
\text { Sierra Club } \\
\text { Trade } \\
\text { Associação }\end{array}$ \\
\hline
\end{tabular}

Quadro 1: Grade clássica dos stakeholders

Fonte: Adaptado de Freeman (1994, p. 62)
Freeman (1984) adverte que não basta analisar os stakeholders por meio da percepção da organização de seu poder e interesse. Quando tais percepções estão em desacordo com as percepções dos stakeholders, todas as boas estratégias pensadas no mundo não funcionam. O problema de congruência é real na maioria das empresas. A análise racional deve ser complementada por um completo entendimento das atividades da organização, através de uma análise de suas estratégias e processos operacionais.

\subsection{Nível Processual}

As organizações grandes e complexas possuem muitos processos para seus serviços. De aplicações de rotinas ou procedimentos e políticas ao uso de ferramentas de análises mais sofisticadas, gerentes inventam processos para realizar as rotinas dos serviços e tornar rotineiras tarefas complexas (FREEMAN, 1984). O autor acrescenta que, para entender as organizações e como elas gerenciam os relacionamentos com seus stakeholders, é necessário olhar para os procedimentos padrões de operação, ou seja, os processos organizacionais que são utilizados para atingir alguma coisa que se adapte ao ambiente externo.

Freeman (1984) enfoca três processos-chave e que devem ser analisados, quais sejam: processo de análise de portfólio; processo de revisão estratégica; e processo de exploração do meio ambiente.

\subsection{Nível Transacional}

A linha final do gerenciamento dos stakeholders, de acordo com Freeman (1984), tem que ser o conjunto de transações que os gerentes nas organizações fazem com seus stakeholders. Como a organização e seus gerentes interagem com os stakeholders? Que recursos são alocados para a interação com cada grupo? O autor acrescenta que a natureza do comportamento dos membros da organização e a natureza da mudança na essência dos bens e serviços são ingredientes-chave para o sucesso das transações da organização com seus stakeholders.

Diariamente, a organização realiza transações com seus grupos de stakeholders, tais como venda de produtos aos clientes, compra de suprimentos de seus fornecedores, pagamento de dividendos a seus 
acionistas ou negociação de um novo contrato com o sindicato. Mesmo quando a organização sai dessa zona de conforto das transações para negociar com algumas mudanças que tenham ocorrido nos stakeholders tradicionais de mercado e o aparecimento de novos grupos de stakeholder, é pouco surpreendente que essas transações se desfaçam. A carência de adequação das transações de uma organização com seus processos e seus processos com seu mapa dos stakeholders é uma fonte real de descontentamento. (FREEMAN, 1984)

Cabe destacar que, se os gerentes organizacionais ignorarem certos grupos de stakeholder no nível racional e processual, então existirá pouco a se fazer no nível transacional. Encontros entre a organização e stakeholder serão, por um lado, breves, esporádicos e hostis e, por outro, não existirão, se outra empresa pode suprir suas necessidades. Para obter sucesso nas transações com seus stakeholders, as empresas precisam ter como base o entendimento da legitimação do stakeholder e possuir processos rotineiros em face de seus interesses. (FREEMAN, 1984)

Aproximadamente 14 anos após o desenvolvimento da abordagem de Edward Freeman, Ann Svendsen desenvolve o seu modelo das relações corporativas com os stakeholders.

Svendsen (1998) sugere uma abordagem colaborativa para construir relacionamentos com os stakeholders, pois esta considera tais relacionamentos como recíprocos, envolventes e mutuamente definidos. O gerente não está separado do relacionamento com os stakeholders, mas é parte dele. Assim, a ideia de gerenciar os relacionamentos não é somente impossível, mas também, é considerado improdutivo para ambos, a organização e seus stakeholders, com o passar do tempo.

A autora complementa, afirmando que um modelo colaborativo sempre assume que os relacionamentos com os stakeholders podem ser uma fonte de oportunidades e de vantagens competitivas. Relacionamentos podem incrementar a estabilidade organizacional num ambiente turbulento, aumentar seu controle sobre circunstâncias variáveis e expandir sua capacidade ao invés de diminuí-la.

Existem vantagens significativas ao adotar uma abordagem mais integrada e holística para identificar e construir estrategicamente relacionamentos importantes com os stakeholders, quais sejam: aumentar a efetividade e a consistência de reação da organização, bem como, permitir que uma organização construa, numa sinergia que ocorre em uma relação positiva com um grupo de stakeholder, como exemplo, a comunidade local, começa a exercer impactos positivos em outro grupo de stakeholder, como é o caso dos clientes. (SVENDSEN, 1998)

Svendsen (1998) critica a teoria de Freeman afirmando que o objetivo principal da gestão dos stakeholders é cuidar para que a organização seja protegida dos impactos negativos das atividades dos stakeholders, bem como enfoca mecanismos para as organizações entenderem e responderem às demandas de seus stakeholders. Gerentes se consideram poderosos para dirigir e controlar interações entre a organização e seus stakeholders. Essa perspectiva, segundo a autora, fragmenta a atenção destinada aos stakeholders, ou seja, separa a atenção em divisões, como por exemplo, o departamento de recursos humanos se responsabiliza pelas relações com os funcionários, o departamento de marketing lida com os clientes, o departamento de relações públicas lida com a mídia, e assim por diante. Com isso, ao invés de os relacionamentos entre gerentes e stakeholders serem moldados pelos valores e metas da organização, eles são moldados pelos interesses e valores dos gerentes dos departamentos.

O quadro a seguir apresenta as características das duas abordagens, a de Freeman (Gestão dos Stakeholders) e a de Svendsen (Relações Corporativas com os Stakeholders).

\begin{tabular}{|l|l|}
\hline \multicolumn{1}{|c|}{ Gestão DOS STAKEHOLDERS } & $\begin{array}{c}\text { RELAçõES CoRPORATIVAS COM } \\
\text { OS STAKEHOLDERS }\end{array}$ \\
\hline Fragmentada & Integrada \\
\hline Foco nas relações gerenciais & $\begin{array}{l}\text { Foco na construção dos } \\
\text { relacionamentos }\end{array}$ \\
\hline $\begin{array}{l}\text { Ênfase na proteção } \\
\text { da organização }\end{array}$ & $\begin{array}{l}\text { Enfase na criação } \\
\text { de oportunidades e } \\
\text { benefícios mútuos }\end{array}$ \\
\hline $\begin{array}{l}\text { Relacionado a metas } \\
\text { de curto prazo }\end{array}$ & $\begin{array}{l}\text { Relacionado a metas } \\
\text { de longo prazo }\end{array}$ \\
\hline $\begin{array}{l}\text { A implementação } \\
\text { idiossincrásica depende dos } \\
\text { interesses das divisões e } \\
\text { estilo pessoal do gerente }\end{array}$ & $\begin{array}{l}\text { Abordagem coerente } \\
\text { dirigida pelas metas do } \\
\text { negócio, missão, valores, e } \\
\text { estratégias corporativas }\end{array}$ \\
\hline
\end{tabular}

Quadro 2: Características da antiga e da nova abordagem das relações corporativas com os stakeholders Fonte: Adaptado de Svendsen (1998, p. 4) 


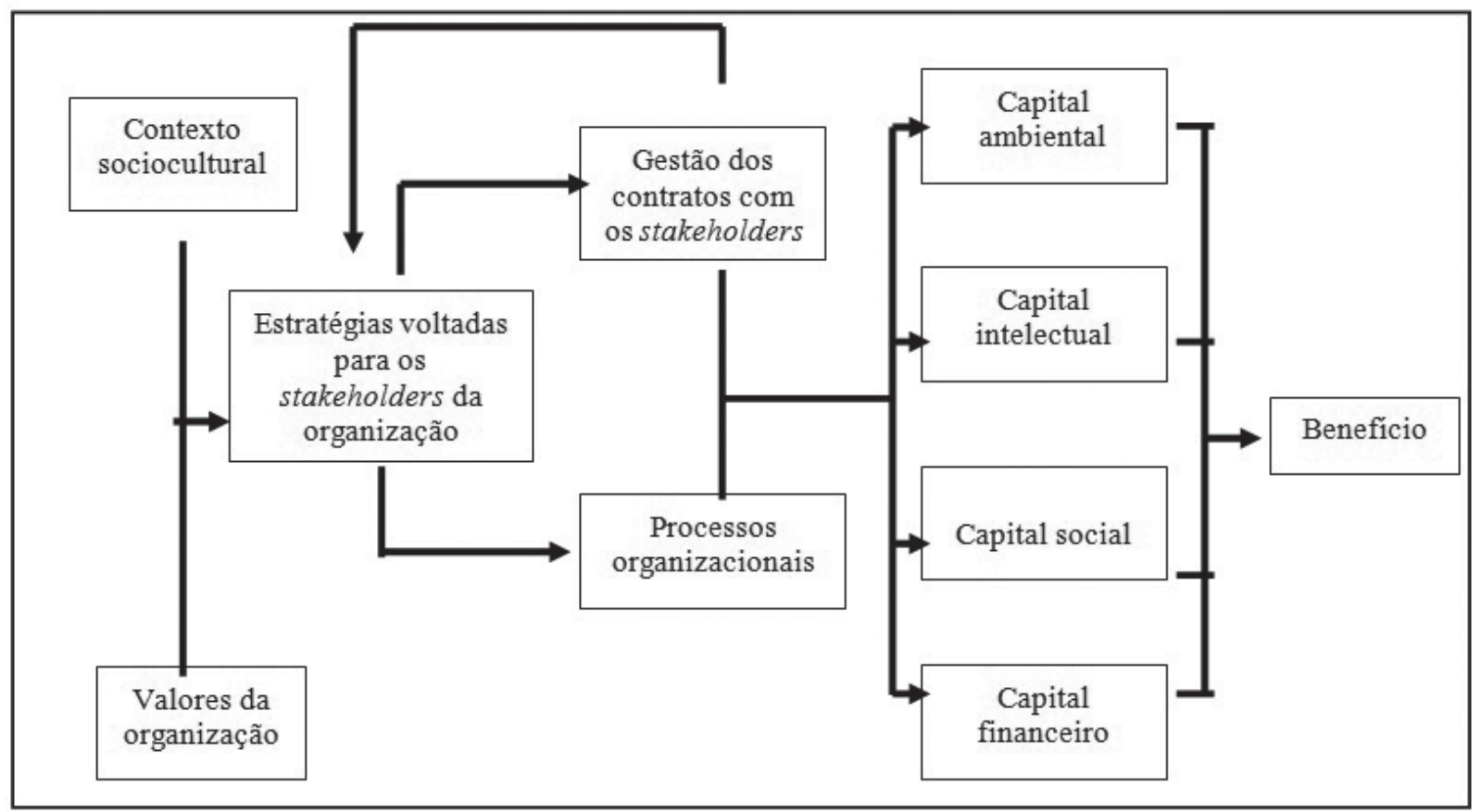

Ilustração 2: Um modelo de relações corporativas com os stakeholders Fonte: Adaptado de Svendsen (1998, p. 44)

O modelo das Relações Corporativas com os Stakeholders, do qual compreende o ciclo de atividade da organização, desde a pesquisa e estratégia de desenvolvimento até o design e implementação dos processos, ilustra como cada stakeholder e relacionamentos com stakeholders influenciam as atividades da organização, como mostra a Ilustração 2 .

$\mathrm{O}$ modelo em questão é baseado em uma visão sistêmica da corporação em sociedade e a ideia é que as empresas são engajadas, tanto ativa quanto passivamente, nos relacionamentos com seus stakeholders. Relações corporativas com os stakeholders são consideradas envolventes, mutuamente definidas e governadas por contratos implícitos e explícitos. Esses contratos, dos quais frequentemente não são mencionados e são subjetivos para o avanço das negociações, especificam o que cada parte espera do relacionamento e o que eles darão em troca. (SVENDSEN, 1998)

Svendsen (1998) afirma que relacionamentos com os stakeholders são considerados o sangue vital da organização e faz uma metáfora com outros organismos vivos, dos quais mantêm relações simbióticas com seu ambiente, pois fornecem a energia, a informação e os recursos necessários para a sobrevivência da empresa. Através desses relacionamentos, a empresa cria capital social, intelectual, ambiental e financeiro - todos essen- ciais a sustentabilidade de longo prazo e crescimento organizacional.

Existem, ainda, algumas características dos stakeholders a serem observadas pelos gerentes organizacionais e, dependendo delas, eles irão prestar mais ou menos atenção a um determinado grupo de stakeholders. São elas: legitimação - o grupo de stakeholders possui um clima moral, ético ou legal na organização? Poder - o grupo de stakeholders possui poder para afetar a organização? Qual o grau de urgência que o grupo ou o indivíduo representa - o stakeholder está fazendo pressão para uma ação urgente? O grupo demanda imediata atenção por parte da organização? (SVENDSEN, 1998)

Após três anos, em 2001, Steven Walker e Jeffrey Marr observaram que não basta gerir os stakeholders e manter relações corporativas com eles, assim, os autores acrescentaram um elemento essencial a esse processo que é o comprometimento com os strakeholders organizacionais.

Walker e Marr (2001) acreditam que a era do poder do stakeholder chegou e deve se tornar uma estratégia de negócio. Segundo eles, os gerentes estão dando mais atenção às pessoas do que aos elementos tradicionais da organização $e$ a seus indicadores de sucesso. Assim, essa abordagem objetiva ir diretamente 
ao centro do significado de relacionamento, o que significa obter comprometimento das pessoas.

Porém, Walker e Marr (2001) destacam que obter e sustentar o comprometimento nos relacionamentos não é tarefa fácil nem simples, mas o resultado é compensador. Atualmente, o que agrada os proprietários e os stakeholders é a performance organizacional, mas ela pode ser alcançada, de uma maneira inovadora, também para os stakeholders da organização. E o contrário também é verdadeiro, ou seja, quando a organização ganha o comprometimento de seus stakeholders, ela aumenta sua performance e cresce, além de o valor da ação aumentar com o passar do tempo. (WALKER; MARR, 2001)

A construção do comprometimento e da lealdade entre os stakeholders se dá através da promoção do desenvolvimento, elucidando os elementos essenciais para o sucesso das relações nos negócios. Tais relações envolvem quatro diferentes estágios, iniciando com a ciência dos stakeholders de que a sua empresa existe e terminando com o desejo de ação destes. O último objetivo de um líder é ganhar o apoio das pessoas. A natureza desse apoio depende do papel do indivíduo, podendo ser um cidadão interessado da comunidade, um cliente, um investidor, um fornecedor ou outro parceiro, um empregado e assim por diante. Não importa o tipo de stakeholder, o importante é a necessidade de se entender a profundidade do relacionamento $e$ o apoio deste stakeholder. (WALKER; MARR, 2001)

Walker e Marr (2001) acrescentam que a natureza deste apoio pode também ser chamada de lealdade, mas o objetivo de se conseguir lealdade verdadeira é uma "faca de dois gumes". Lealdade verdadeira não significa somente ganhar o apoio das pessoas (ou que elas apoiem a organização), mas sim, de suas cabeças e mentes (o que elas pensam da empresa). Porém, para alcançar tal apoio é necessário estabelecer confiança e, para isso, a empresa deve ter uma integridade visível e possibilitar a construção de uma forte reputação corporativa todo o tempo.

Para se gerenciar os relacionamentos nos negócios e a lealdade dos stakeholders, além de levantar os custos da perda de um stakeholder, deve-se entender o que conduz a lealdade (ou a falta dela). Esse aprendizado inicia quando a organização vê que essa lealdade é mais do que um simples comportamento, ou seja, ela é mais do que simplesmente escolher em ficar com uma organização, seja um empregado, um comprador, um investidor ou um fornecedor. Para Walker e Marr (2001), o melhor conceito de comprometimento (os autores utilizam os termos comprometimento e lealdade como sinônimos) é dos professores John Meyer e Natalie Allen, da Western Ontário Iniversity, que identificaram três tipos de comprometimento, são eles:

a) Emocional (afetivo) - ter sentimentos por uma organização, querer se associar a ela e se identificar com seus objetivos e princípios etc.

b) Baseado em custos (permanência) - avaliar os custos de uma curta associação realizada com uma organização, e sentir que se deve ficar.

c) Baseado em obrigação (normativo) - sentir obrigação de permanecer associado a uma organização; sentir uma responsabilidade, ou que se deve ficar com uma organização porque é a coisa certa que se há de fazer.

A pesquisa dos dois professores mostrou que em relação à retenção, assistência, performance e direitos e deveres, o tipo de comprometimento que trouxe resultados mais favoráveis foi o emocional, ou seja, é melhor ganhar o comprometimento dos funcionários fazendo com que eles queiram estar lá, ao invés de tê-los se sentindo trancados na empresa. Eles ficarão muito tempo com a organização e serão mais produtivos. (WALKER; MARR, 2001)

De acordo com Walker e Marr (2001), a equação da lealdade (um endosso do stakeholder referente a sua empresa, expressando com uma garantia, implícita ou explícita, a continuidade do relacionamento, ligado com uma atitude de comprometimento); é representada pela soma do comprometimento (atitude - uma atração emocional ou psicológica por uma empresa, resultado de uma interação positiva entre os stakeholders); com o comportamento (continuar com - ações dos stakeholders demonstrando uma manutenção ou um aprofundamento da relação com sua empresa).

Assim, lealdade requer o claro entendimento da posição dos stakeholders e o que eles pensam sobre o relacionamento com a empresa. Deve-se aprender como se avalia o estado atual e a inclinação dos stakeholders para saber como proceder com eles nas relações. (WALKER; MARR, 2001)

Os autores acrescentam que os stakeholders devem ser classificados e valorados de acordo com os diferentes níveis de comprometimento e apresentam 
uma matriz de lealdade dos stakeholders, representada na ilustração a seguir.

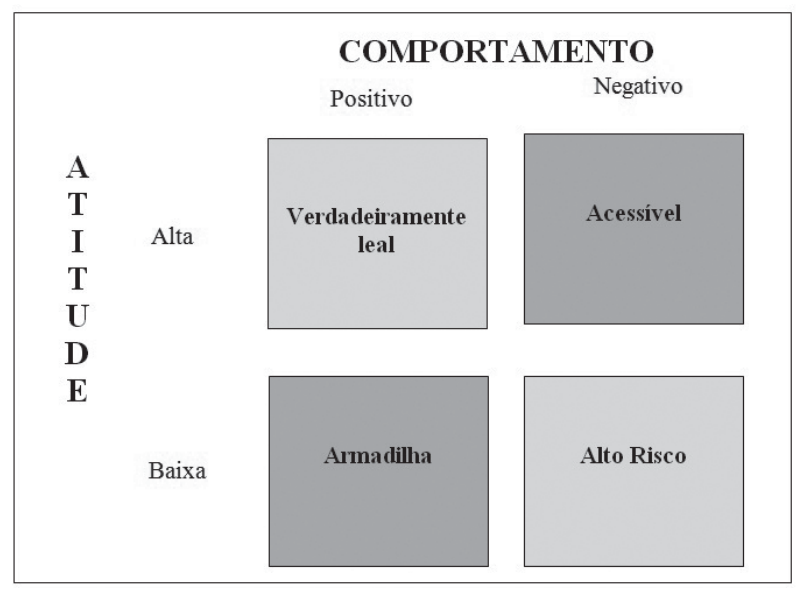

Ilustração 3: Matriz de lealdade dos stakeholders

Fonte: Adaptada de Walker e Marr (2001, p. 52)

De acordo com a matriz, existem quatro possíveis combinações para se classificar os stakeholders:

a) Verdadeiramente leal - é o ideal. É quando se consegue dos stakeholders, além de um comportamento leal, os seus corações e suas mentes. Eles gostam do relacionamento com a empresa e pretendem continuar ou aprofundá-lo. Esses são os stakeholders estratégicos, e a empresa tem de maximizar a proporção deles.

b) Acessível - eles gostam de você e estão abertos e acessíveis a seus esforços de ganhar a lealdade deles. Possuem uma atitude positiva sobre o sentido de seu relacionamento com a empresa, mas não planejam aprofundá-lo ou continuá-lo definitivamente. Em muitos casos, suas razões em não aprofundar o relacionamento pouco ou nada têm a ver com a empresa ou do relacionamento dela com eles. A empresa nem sempre é capaz de eliminar as barreiras para um longo relacionamento com este tipo de stakeholder, mas sabendo que eles existem e encontrando-os, ela se coloca em posição de remover barreiras e tentar novos incentivos em vez de ficarem chocados e desapontados quando eles os abandonam. Esses stakeholders estão basicamente satisfeitos com o relacionamento com sua empresa, o que faz eles estarem abertos à comunicação $e$ atenção da empresa para aumentar sua lealdade. Em pouco tempo eles podem migrar para o grupo verdadeiramente leal. c) Armadilha - eles não estão favoravelmente dispostos em relação à empresa e não estabeleceram um relacionamento positivo com ela. O que intriga sobre esse segmento é que eles ainda exibem lealdade por meio de seu comportamento. Ainda que particularmente eles não queiram estar associados à empresa, eles têm indicado que estarão por pouco tempo com ela, até quando interessar. Eles poderão terminar o relacionamento com a empresa antes de acabar o tempo previsto, se a situação for favorável. Eles continuam consumindo os recursos $e$ a atenção da empresa, mas não necessariamente contribuem para o sucesso dela em longo prazo. Por outro lado, representam uma oportunidade durante o tempo que permanecerem com a empresa. Se forem importantes para a estratégia de longo prazo, seria bom identificar como mantê-los satisfeitos. Se essa situação modificar e a empresa tiver controle, então contramedidas deverão ser tomadas para mudar a opinião deles e movê-los para a categoria verdadeiramente leal. Se o custo de se criar à satisfação exceder o benefício potencial para o relacionamento saudável com este stakeholder, a empresa pode decidir que acabar com o relacionamento pode ser bom para ambas as partes.

d) Alto risco - eles não são favoráveis sobre o relacionamento que possuem com a empresa e planejam encerrá-lo em seus próprios termos. Assim, o ideal é que a empresa não possua nenhum stakeholder desSe grupo. O importante, nesses casos, é, em vez de simplesmente cortar este stakeholder, iniciar diálogo para sanar qualquer mal entendido.

Os autores ainda citam quatro estágios dos quais passam os relacionamentos de sucesso com os stakeholders de uma organização, quais sejam:

a) Atenção - significa que o stakeholder sabe que a empresa existe e se interessa por ela por algum motivo.

b) Conhecimento - o stakeholder busca informações sobre a empresa.

c) Admiração - após conhecer a empresa, o stakeholder começa a admirá-la. Nesse ponto, ele desenvolve a atitude de lealdade ou comprometimento e quer se associar à empresa. 
d) Ação - ela somente acontece por meio dos stakeholders que estão no topo da matriz de lealdade: os grupos verdadeiramente leais ou acessíveis, dos quais a atitude indica comprometimento (admiração) para com a organização. Se eles estão acessíveis é por algum motivo fora do controle da empresa. Os verdadeiramente leais estão prontos para apoiar a organização mais do que antes, pois a empresa conquistou a sua confiança.

\section{Considerações Finais}

Diante do exposto, fica evidente a importância $e$ a influência dos stakeholders de uma organização para a sua sobrevivência. Porém não são todos iguais e eles nem têm os mesmos interesses e expectativas com a organização. Identificar quem são, o que buscam e como atendê-los é responsabilidade de cada organização, utilizando ferramentas e modelos para buscar essas informações e traçar suas estratégias de relacionamento $e$ de atendimento às necessidades $e$ expectativas de cada grupo de interesse.

Salienta-se que qualquer esforço na utilização de estratégias baseadas nos stakeholders deve ter clareza quanto a quais atores priorizar para que atores importantes não sejam descartados nas análises. Para tanto, os modelos e enquadramentos apresentados são ferramentas úteis para auxiliar na gestão desses grupo de interesse.

Os modelos expostos são alguns exemplos de como as empresas posdem lidar com os grupos e indivíduos que as afetam ou são afetados por elas. Recomenda-se que a organização utilize uma mescla dos três, ou seja, deve identificar seus stakeholders, conhecê-los, levantar seus interesses, incluí-los em seus processos, manter uma relação recíproca e ainda obter o comprometimento deles, localizando-os em uma matriz de lealdade, para a priorização deles, considerando suas especificidades e a necessidade de adaptação de cada modelo à sua realidade.

\section{REFERÊNCIAS}

\section{ALPERSTEDT, G. D. Adaptação estratégica em}

organização universitária: um estudo qualitativo na Universidade do Sul de Santa Catarina. 2000. 249f.

Tese. (Programa de Pós- Graduação em Engenharia de Produção). Universidade Federal de Santa Catarina.

Florianópolis, 2000.

BOWDITCH, J. L.; BUONO, A. F. Elementos de comportamento organizacional. São Paulo: Pioneira, 1992.

CARROL, A. Business and society: ethics and stakeholder Management. Cincinnati: South- Western Publishing, 1993.

CROZIER, M.; FRIEDBERG, E. L'Acteur et le système. Paris: Editions du Seuil, 1977.

FREEMAN, R. Edward. Strategic management: a stakeholder approach. Boston, MA: Pitman, 1984.

GIBSON, Kevin. The moral basis of stakeholder theory. Journal of Business Ethics. Dor - crecht, aug. 2000.

KATZ, D.; KAHN, R. Psicologia social das

organizações. 3. ed. São Paulo: Atlas, 1987.

KLUGE, César Augusto; PEPPLOW, Luiz Amilton.

Stakeholders. [2005]. Disponível em: < http://pessoal. cefetpr.br/lapeplow/paginas/stakeholder.html $>$. Acesso em: 5 maio 2005.

\section{MILES, R. H. Macro organizational behavior.}

Glenview, Illinois: Scott Foresman and Company, 1980.

OLIVEIRA, Djalma de Pinho Rebouças de.

Planejamento estratégico: conceitos, metodologia e práticas. São Paulo: Atlas, 2013, p. 26.

PERROW, C. Análise organizacional: um enfoque sociológico. São Paulo: Atlas, 1972.

PETROCCHI, Mário. Gestão de pólos turísticos. São Paulo: Futura, 2001.

PFEFFER, J.; SALANCIK, G. R. The external control 
of organizations: a resource dependence perspective.

New York: Harper \& Row Publishers, 1978.

STONER, J. A. F.; FREEMAN, R. E. Administração. Rio de Janeiro: Prentice-Hall do Brasil, 1995.

SVENDSEN, Ann. The stakeholder strategy: profiting from collaborative business relationships. EUA, São

Francisco: Berrett-Koehler Publishers, Inc., 1998.

WALKER, Steven F; MARR, Jeffrey W. Stakeholder power: a winning strategy for building stakeholder commitment and driving corporate growth. Cambridge: Perseus Publishing, 2001. 